\title{
Editorial
}

\section{Antiphospholipid Syndrome (APS)}

\author{
Seth Mark Berney ${ }^{*} \S$
}

Division of Rheumatology, University of Arkansas for Medical Sciences, 4301 West Markham Street \#509, Little Rock, Ar 72205-7199, USA

In 1983, Graham R V Hughes, MD published a 2-page article in the British Medical Journal entitled "Thrombosis, abortion, cerebral disease, and the lupus anticoagulant" [1]. This is generally acknowledged as the first report associating the antibodies subsequently named the antiphospholipid antibodies (aPL) with multiple clinical occurrences, now known as the Antiphospholipid Antibody Syndrome (or Hughes Syndrome). The aPL reflect a heterogeneous collection of antibodies which cause/contribute to the pathologic manifestations, as well as the "false positive Veneral Disease Research Laboratory (VDRL)" test and the misnomer "lupus anticoagulant". Since that initial publication, many groups have expounded upon Dr. Hughes' observation leading to 14 International Congresses on aPL. During these meetings, clinical and research observations were presented and discussed and diagnostic criteria were proposed and refined. The most recent congress occurred in 2013 in Rio de Janeiro and the $15^{\text {th }}$ is planned for 2016 in Istanbul.

Conventionally, the aPL is viewed as a procoagulant and is frequently associated with rheumatologic diseases, such as systemic lupus erythematosus. Thus, this condition has been primarily the responsibility of rheumatologists and hematologists. However, since 1983, we have recognized

*Address correspondence to this author at the Division of Rheumatology, University of Arkansas for Medical Sciences, 4301 West Markham Street \#509, Little Rock, AR 72205-7199, USA;

Tel: 501-686-5586; E mail: SBerne@uams.edu

${ }^{\S}$ Guest Editor: that the aPL can affect multiple other organ systems including the female reproductive tract and the kidney. In order to better educate physicians and demystify this condition, the editors of The Open Urology \& Nephrology Journal decided to publish this thematic edition dedicated to the Antiphospholipid Antibody Syndrome. As a consequence, this issue contains 5 separate articles written by leaders of the field:

1. The Pathophysiology of Antiphospholipid Syndrome.

Pablo Ruiz Sada, Hannah Cohen and David Isenberg

2. Diagnosing Antiphospholipid Antibody Syndrome- A Review of the Crterion for Definite APS

Jeffrey S. Dlott

3. Antiphospholipid Syndrome (APS) - An Update on Clinical Features and Treatment Options

Mamatha Katikaneni, Meera Gangam, Seth Mark Berney and Sarwat Umer

4. Obstetrical Considerations and Management of Antiphospholipid Syndrome

Karen J. Gibbins and Robert M. Silver

5. Antiphospholipid Antibodies and APS Nephropathy

Rohan Willis and Emilio B Gonzalez

\section{REFERENCE}

[1] Hughes GR. Thrombosis, abortion, cerebral disease, and the lupus anticoagulant. Br Med J (Clin Res Ed) 1983; 287(6399): 1088-9.

(C) Seth Mark Berney; Licensee Bentham Open.

This is an open access article licensed under the terms of the Creative Commons Attribution Non-Commercial License (http://creativecommons.org/licenses/by-nc/3.0/) which permits unrestricted, non-commercial use, distribution and reproduction in any medium, provided the work is properly cited. 